\title{
Causes and Forms of Marginalization: An Investigation of Social Marginalization of Craft Workers in Dembecha Woreda, North Western Ethiopia
}

\author{
Haregewoin Tiruye \\ Department of Psychology, Debre Markos University, PO, box: 269, Debre Markos, Ethiopia
}

\begin{abstract}
This paper is primarily concerned to investigate the causes and forms of social marginalization of craft workers living in Dembecha Woreda in North Western Ethiopia. The study has been carried out in two purposely selected villages in Dembecha Woreda. A cross sectional qualitative method was employed (in-depth interview and Focus Group Discussion) involving a total of 44 participants 26 key informant, and 3 FGD comprising 6 individuals in each group through purposive and snowball sampling techniques. Accordingly, the causes for marginalization of craft workers are mainly socio-cultural constructions retained in negative stereotypes, and evil eye ideology stemmed from the perception of the non-craft worker society. Thus, potters are highly associated with evil eye whereas tanner's stereotype is associated with 'impurity'. Craft-workers were marginalized in many forms mainly, restriction from social associations, restriction in intermarriage with the non-craft workers, and spatial segregation. Moreover, craft workers of Dembecha Woreda are marginalized occupational groups who are socially excluded, culturally subordinated, and spatially segregated. Nowadays some forms of marginalization are declining and hence there is spatial integration and intermarriage. Finally it is recommended that, interventions are needed like public and religious teaching to change the belief of the society, promoting 'indigenous crafts' through culture and tourism, and the government should design programs to teach the society about equality.
\end{abstract}

Keywords: marginalization, social exclusion, craft worker, potter, tanner, stereotype, prejudice

DOI: $10.7176 /$ RHSS/9-21-02

Publication date: November $30^{\text {th }} 2019$

\section{INTRODUCTION}

Handcraft working has a long history in producing the most vital utilities associated with the daily lives of both urban and rural communities in Ethiopia (Mulu, 2007). Despite this Craft working is identified as dishonored occupation and workers are marginalized (Damtew, 2000). Ethiopian Human Rights Council, (2009) noted in Ethiopia not only ethnic minorities (like wayto and Felasha in Amhara, waata in Oromia, manjo and manna in Kefa, and fuga in Yem) but also occupational minorities of craft workers are exposed to marginalization due to their occupation. Admas (2000) pointed marginalization is the most dangerous form of oppression, people expelled from useful participation in social life and subjected to severe material deprivation. Pankhurst (2001) stated that marginalization is expressed in negative stereotyping, polluting and mythological justifications. Additionally, Reminick (1978) and Finneran, N. (2003) explained that craft workers are associated with evil eye that the group and the occupation are looked down. Freeman and Pankhurst (2003) stated that manifestations of marginalization are restrictions on exchanges, social interactions and consumptions of food and drink; segregation in burial; and beliefs about craft workers' evil spirit powers. Thus, craft workers usually occupy the lower status of the social hierarchy.

The relationship between craft workers and the community is characterized by social distance and negative characterization. Thus includes, stereotype, prejudice, and discrimination are important in conceptualizing the pattern of relationships ( Epple Susanne (2018),Lewis (1970) and Akalework,(2014).

Hoben (1970) divided the stratification of the Amhara society in to three social categories craft workers were assigned in the lowest status. Due to this they are subordinated by the community.

In Ethiopia, the present and previous governments have made many efforts to establish equality and integration of excluded groups. Today, churches run numerous awareness-raising programmes and some national and international NGOs and activist groups are also active in the country (Freeman and Pankhurst 2001). Yet, as many studies show, marginalization continues to exist.

In the past, research about craft workers marginalization is conducted from various perspectives. These includes approaches of social structure like cast in India, and social stratification in Amhara society, symbolic approach that focus on pollution and fertility in South Ethiopia and others (Pankhurst,1995). But craft workers marginalization in Northern Ethiopia is not studied from the society's socio-cultural belief perspective.

According to Epple Susanne (2018) the categorization that have been used before have focused on either the occupational groups or the majority society. It is impossible to make correlations between categories based on either the type of craft or the form of the majority society. It is illogical to correlate craftwork with 
marginalization based on the occupation they carry out. Because, different farmers produce craftworks like house-building, thatching and rope-making.

Marginalized occupational groups in Northern Ethiopia have not been studied from different perspectives in previous literatures. The Falasha and Negede Wayto, have been only studied from sociological and/or historical perspectives. The gap seems to be far more pronounced with regard to craft workers who live scattered among the Amhara majority throughout the region. With the exception of craft workers in Menze society (monastic community) in North Shewa studied by Damtew(2000)the researcher cannot found studies from different perspectives about the causes of marginalization of craft workers. The researcher also does not get any proved evidence from previous studies in Northern Western Ethiopia about the reason to categorize craft workers as marginalized occupational minorities. Sothat, this study is conducted from the perspective of the non-craft community's belief and ideology.

Moreover, Tamiru, (2017) pointed out that earlier studies about craft workers were conducted and interpreted at national and regional level. But marginalization is multidimensional and dynamic it should be studied contextually in smallest administration unit like kebele or village level. Thus, this study is conducted at the smallest unit in village level.

Dembechaworeda is found in Amhara region North West Ethiopia; people living here have uniform language, culture, communalities and values. This Woreda is known in different craft work products but craft workers are socially and culturally subjected to marginalization. Specifically, in the town of Dembecha there are two known two distinct villages of craft workers mainly Wotebet and Arogea Amba. There are manifestations of marginalization in spatial, social and cultural dimensions in these two villages. Thus, study is conducted in West Gojjam, Denmbecha woreda at these villages. The reason to select these villages is, the researcher was born and lived there for 20 years and have been observing the separate villages of craft workers in my localities for long. In addition, within Dembecha Woreda, craft workers are identified and called by derogatory names and honor degrading titles. For instance, the tanners as 'faqi' (scratchers), and the potters as 'debenansa' (taker of the fertile soil). These terms are generally used to mention the lower status of craft workers while implicitly reinforcing the 'dominant' society's sense of superiority. As a result, the researcher has adequate knowledge and experience about social marginalization of craft workers.

This study emphasized on the exploration of the stereotypical categorization of craft workers as marginalized according to the way that they are stereotyped by the majority. Thus, this research stressed to give comprehensive evidence on the current condition of craft workers (potters and tanners) in line with the forms of marginalization.

\section{Research Method}

\subsection{Design of the Study}

The research employed descriptive research design due to the fact that it is appropriate to come across the prevailing social dimensions of marginalization that characterize Dembecha Woreda craft workers. The data for this knowledge construction contained the key participants of the study (craft workers), the nearby community leaders, and elderly people who could give authentic information about the issue under investigation

\subsection{The Study Area}

This study was conducted in DembechaWoreda of West Gojjam administrative zone in AmharaRegional State.DembechaWoreda is located $350 \mathrm{~km}$ from Addis Ababa and $205 \mathrm{Km}$ from Bahir Dar the capital of Amhara Regional State. West Gojjam, where Dembecha Woreda is found, is one of the administrative zones of Amhara regional state situated to the north of Addis Ababa. According to CSA (2007) the Woreda has a total population of 129,228 , of which the majority live in rural areas and small number are urban dwellers.

Economically, the majorities are sedentary agriculturalists, who largely depend on cereal farming which is practiced by ox-drawn plough. Many people in the town are engaged in small scale trade. Besides, theWoreda is known for its Areki, which is increasingly generating income for many families, and it dominates the local market.

\subsubsection{Subjects of the study}

The primary study subjects of this study are craft workers engaged in pot making and tanning who are living in the two distinct village of ArogeAmba and Wotebet found in the out skirt of the town. Though there are craft workers who live dispersed in different kebeles in the Woreda due to financial and other constraints the study carried out on two well-known villages of craft workers ArogeAmba and Wotebet were selected purposefully.

\subsubsection{Sample and Sampling procedure}

For this research purposive sampling technique was used in order to select44 individuals from the two villages as total sample size .Hence, 26 individuals were selected for in-depth interview based on their willingness and seniority, both from craft workers and non- craft individuals who can provide rich information from their life experiences about the existing social marginalization of tanners (skin workers) and potters (pot makers). The 
researcher also conducted 3 FGDs constituting 6 individuals in each group to obtain evidence on their social relations, their view about themselves, attitude towards the non-craft people, causes of marginalization, and forms of their marginalization. A total of 18, participants that were not included in the interview, in 3 FGD held at each of the selected sites.

\subsubsection{Data Collection tools}

In order to meet the objective and to answer the research questions the researcher used different qualitative data collection tools which enable to obtain rich information about the issue under investigation. In-depth interviews, focus group discussions and observation were employed.

\subsubsection{Data Analysis}

The collected qualitative data through interview and FGD was organized based on the research questions to develop a sense of data. Then the researcher developed codes and categories and reduced the large data in to manageable sets of themes. Finally, it was analyzed qualitatively through careful interpretation of meanings and contents.

\section{RESULTS AND DISCUSSION}

The causes of craft workers marginalization are social constructions retained in negative stereotypes and evil eye ideology. They were marginalized in the forms of restriction from social associations, restriction in intermarriage and spatial segregation. Thus, efforts were made to investigate the cause and forms of marginalization by incorporating such components.

\subsection{Causes of Craft Workers Marginalization}

\subsubsection{Associating Craft Workers with Evil Eye}

People in the study area associate Evil Eye with potters and every one believed that potters possess the evil spirit through inherence. Eye contact is believed to be essential for the 'buda' people to attack the potential victim. In other words, the evil eye attack is thought to be accomplished by eye gaze. Though eye gaze is believed to be essential, every eye contact with the'buda' people does not mean an attack. The interviewed non-craft workers reported that the society thought that ' $b u d a$ ' people conceal their human identity while digging the grave. In addition, it is believed that entrails of a person died of evil eye attack is 'eaten' by the 'buda' people. One key non-craft informant describes this situation as:

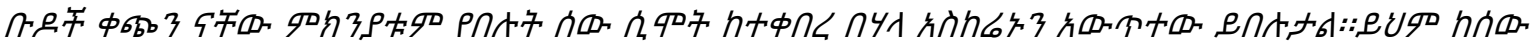

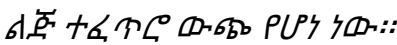

Buda people are physically thin due to their taboo or unnatural eating habit. And that is why corpse of a person who died off evil eye attack is usually taken out of the grave by these people to eaten.

The above explanation assumes the alleged different character they possess. In addition the notion of ' $b u d a$ ' affects personal relations. Concerning the belief of the society, one key informant from craft workers disclosed her experience as:

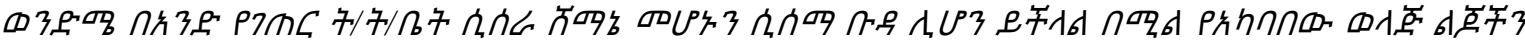

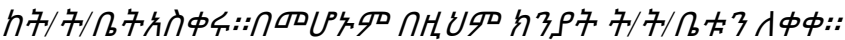

My brother was a teacher in one elementary school in a rural kebele. The parents of the students do not want to send their children to school because they heard that there is a craft worker who teaches in the school. They think that he may be buda and he will attack the children in the school. As soon as he heard that he wants to leave the school and finally he is transferred to another school.

Due to the fear of evil eye attack the society maintains physical distance and thus craft workers social relationships are affected consistent with Finneran, N. (2003). Besides, FGD participants of the craft workers expressed that, they are stereotyped as jib galabi /hyena rider / because it is assumed that 'buda' people ride hyena to reach the grave of the deceased. This seems a symbolic attachment with a negatively perceived animal, hyena. In the study area hyena is considered as something having magical force, and its name is employed to refer negative trait.

Generally, the finding revealed that, the non-craft society discourages interpersonal relations and physical contact with craft workers who are believed to have evil spirit. Sometimes, being conscious of such fear, the 'buda people' prefer alienation similar with Mulu,(2007) and Reminick (1978). Moreover, this study asserted that evil spirit is believed to be inherited. And thus, this beliefs the major cause of marriage restriction with craft workers.

\subsubsection{Negative Stereotyping}

There are different negative characterizations and assumptions that are employed by non-craft people in an attempt to rationalize the marginalization of craft workers. One non-craft people informants disclosed that, craft workers particularly potters are characterized as wasteful and extravagant. They are considered as unable to save their money and are also perceived as thoughtless about their future life. In this regard one non- craft person 
informant reported that:

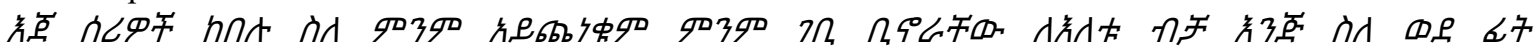

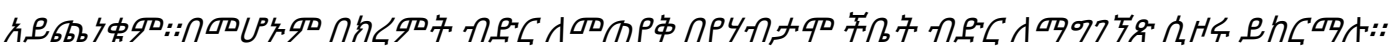

Craft workers do not care about their house, cloth, utensils etc. They are primarily focused on what to be eaten. No matter how much they earn, nothing is left to improve their life during Bega /winter/ season, they look like thousands birr paid government employed. During kiremit / summer/ they are found at the dooryards of riches to borrow money. In fact, since it is a character endowed from their father /keabatyeteworsesilehone/ they cannot change it.

FGD participant from non-craft people expressed that potters particularly perceived to have impure descent and are referred to as atintegodelo('impartial bone') and also/tilayelesh/have no grace/ or tilakelal/light grace/. What the society called tila is not related with one's clothing or physical structure nor to shadow or umbrella. The society thinks that craft workers are not graceful no matter how fat or tall and well-dressed.

Moreover, FGD discussants of tanners described that the negative characterization is associated with the hide they are working with. Due to the nature of their traditional hide work tanners may have bad sniff and they are unclean. This perception of impurity is the major factor for the marginalization of tanners which is consistent with Epple Susanne (2018). One key informant in a similar way from tanners describes his experience as follow: the

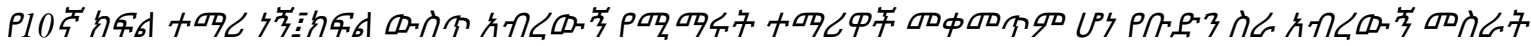

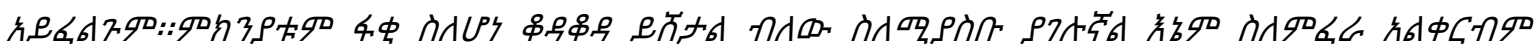

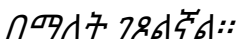

I am a grade 10 student, in the class students do not want to sit with me and to do group assignments because they think I may have bad sniff by associating with skin I am working with. Due to this I always isolate myself kept aside.

The association with 'impurity' keeps tanners aside mainly in the dimensions of physical contact and commensality as similar with Freeman and Pankhurst (2003).Since, tanning is carried out with traditional methods tanners mainly at their work place, have sniff. Hence, I have observed their work place while they work in my field stay.

Tanners are also said to have different facial feature and physical structure .The interviewed elderly from non-craft people expressed the thoughts as follows:

व

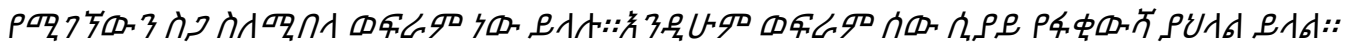

It is said that tanners have partial black face with muscular physical structure. As a result, some one having such features is suspected to have a faki /tanner/descent and referred as fakiyemaselal/looks like a tanner/.

In contrary to this, in actual cases there is no any clearly distinguished physical feature which identifies such people as far as the researcher's field work experience is concerned. Outsider can't notice and identify the tanners from the non-craft people simply by looking the color and physical structure, unless they see them practicing or selling their crafts.

Therefore, from the obtained data the characterizations mentioned above are perhaps allegations to rationalize exclusion or restriction of craft workers participation and involvement in socio-cultural affairs.

\subsection{Forms of Marginalization}

\subsubsection{Restriction in Social Associations}

There are different voluntary associations established and utilized on a reciprocal basis to accomplish different goals in the surrounding community. From this Mahiber the most predominant religious oriented association people gather in an honor of a certain Saint in the Orthodox religion once in a month to eat, and drink.

Many people do not like to eat and drink in tanner's house due to their perception of impurity. Though tanners were invited, non-craft workers do not accept the reciprocal invitation. One key informant from tanners in this regard explained as follows

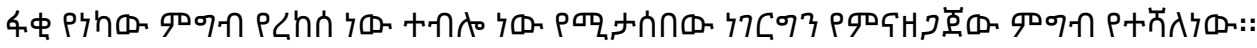

People think that our (tanners) food and drink is impure. According to their view, everything we (tanners) touched is impure. Nevertheless, this is not the truth, we prepare quality food and drink even better than the non- craft people do.

Therefore, commensality was restrictive especially for tanners and they are still facing difficulties to participate in feast oriented associations due to the perception that connects tanners with impurity based on the evidence from the data obtained. And craft workers were not allowed to participate in associations organized among the non-craft people consistent with Freeman and Pankhurst (2003).

Restriction of potters from religious association is due to evil eye ideology. As a result of the fear of evil 
eye attack the society excluded potters from the participation of different religious feast associations. In the course of time certain changes have come to be seen; unlike tanners potters now a day are joining to different Mahibers. Generally from the findings obtained the causes of craft workers restriction from association are ideology of evil eye and impurity

\subsubsection{Marriage Restriction}

Marriage with craft workers is considered as disgraceful. Denial of intermarriage with the chewahas been a salient variable perpetuating low status of craft workers. All the interviewed non- craft workers discussed that the community considers intermarriage with craft workers as 'pollutant'. This is because of the categorization as chewa (commoners) and ejeseri (craft workers). One elder from non-craft people informant in line with this explained as:

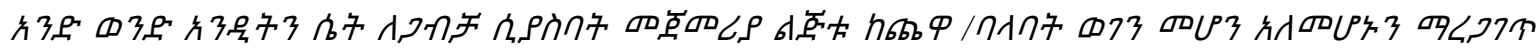

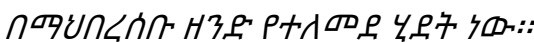

Craft workers are considered as atintegodelo and have impure descent. Marriage with them is not common in this Wordeda. When one wants to marry a girl the first thing that comes to non-craft workers mind is the girl or boy from the chewa or balabat or not. This is a trend from the past and if that person is chewa one can engage unless no one can engage with craft workers.

In addition, FGD discussants of craft workers revealed that inter marriage with non- craft peoples is difficult for us. The strict norm in this Woreda is marriage, it is still forbidden to marry chewa from craft workers. One potter disclosed his life experience regarding this situation as follows:

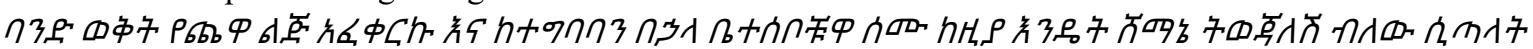
93务々,年3+กடH::

In one time, I fell in love with one girl form the chewa family and we spent two years as friends in a good relationship. After two years her parents heard that she is going to marry a potter. Finally they quarrel with her and she is forced to stop the relationship with me. Thus, we broke our relationship.

The finding of the study also showed that the ideological explanations, craft workers' forced endogamous nature of marriage largely arises from the non-craft workers' avoidance. Thus, evil eye nature and 'impurity' that are maintained through negative characterizations are the main reasons for marriage restriction with craft workers.

The research revealed that marriage restriction initially implies biological segregation by preserving ascribed status. Functionally, the biological exclusion limits and affects other aspects of relation. Thus, forced endogamy in Dembechahas been initial variable employed by the 'dominant' society to keep craft workers aside this is consistent with (Damtew, 2000; Pankhurst, 2003).

Moreover, FGD held among non-craft people pointed out unlike the past, some youngsters began to break the tradition that resulted from culture, now a day intermarriage regarding potters there are changes. The restriction to inter- marriage for young educated person is illogical. That is to say, educated adolescent males from the higher status, the so-called chewagroup marry wives from potters. But the participants justified marriage with tanners is extremely restricted still now.

\subsubsection{Spatial Segregation}

The researcher has observed that, the settlement patterns of craft workers in Dembecha town (Wotebet and ArogeAmba) lies at the outskirt of the town. Craft workers and the name of these sites are inseparable. Mainly, the name Wotebet connotes being craft worker among the people of Dembecha woreda. The interviewed noncraft elder reported that, if someone said I am from Wotebet orArogeAmbahe/ she is more likely to be considered as either a tanner or a potter.

The spatial segregation in Dembecha town is maintained both voluntarily and forcefully. For tanners, settlement at the margins of the town in both villages is necessitated by the nature of their work because it requires sufficient water and to avoid pollution. Accordingly, settlement of tanners in Dembecha follows rivers called Gulla and kusit. Regarding this a key informant tanners pointed out:

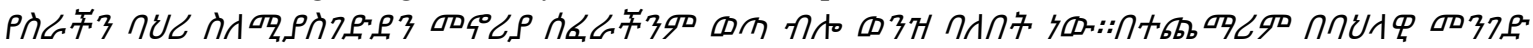

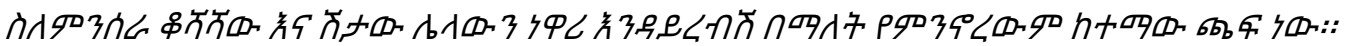

Our house is located far from the town because the nature of the work tanning forced us to settle near the river to get sufficient water. The pattern of settlement in Wotebet and ArogeAmba is to avoid pollution. Tanning is practiced traditionally here because of our poor economy and because this is thought to bring pollution. The smell of skin while making different materials is bad it brings bad sniff and non-craft workers may be disturbed. By taking this in to consideration the settlement pattern is at the margin far from the settlement of the non-craft workers.

Besides, FGD participants from potters describe the settlement of potters in the village of wotebet is said to be forced.

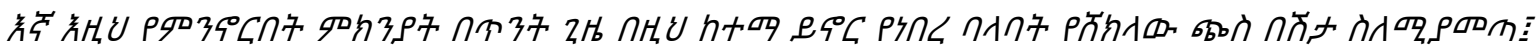




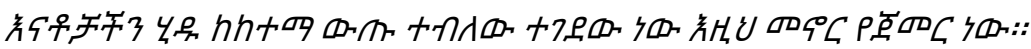

Settlement in wotebet is historical; it is resulted due to the order of the noble man who had lived at the town.

The nobles had believed that the smoke that comes out during firing of pots caused different diseases for nonpotter community. As a result, our mothers were forced to the edge of the town/wotebet/.

As the researcher also observed currently residential intermixing is being observed at the edge of Wotebet non craft people began to settle due to the town's municipality residential land distribution program. This spatial integration may be a mechanism in integrating craft workers with non-craft people.

\section{CONCLUSINS AND RECOMMENDATIONS}

\subsection{Conclusion}

Based on analysis and discussion regarding the social aspect of marginalization that characterizes craft-workers, the following conclusions have been made;

- The social aspects have been the means of exclusion by the non-craft community in restricting craftworkers not to participate in different social affairs. It is found that the major attributes that are accounted for the marginalization of craft workers are mainly social constructions retained in negative stereotypes and evil eye ideology.

- The causes of marginalization stemmed from the perception of the non-craft worker society where the beliefs and explanations are ideal and not justifiable.

- It is found that craft workers are stereotyped in negative characterizations as having poor life style, as being anti-social, wasteful, and unclean. These negative stereotypes are perceived to be inherited characters.

- Moreover, the research revealed that potters are highly associated with evil eye. And the society believed that potters are possessed by inherited evil spirit that threatens life and endangers productivity. Whereas tanners stereotype is associated with 'impurity'.

- Craft- workers were marginalized in many forms mainly, restriction from social associations, restriction in intermarriage with the non-craft people, and spatial segregation. And it is found that, craft workers of Dembecha Woreda are socially excluded, culturally subordinated, and spatially segregated. Additionally, it is found craft workers in Dembecha Woreda are marginalized occupational groups.

- Nowadays some forms of marginalization are declining and hence there is spatial integration of craft workers as well as intermarriage specifically with potters. Changes are also evidenced in increase of craft workers participation mainly potters in various social associations with non-craft people.

\subsection{Recommendations}

Based on the research findings, the following recommendations have been made;

- The causes of marginalization are stemmed from the perception of the non-craft worker society. And the beliefs and explanations are not justifiable. Therefore, concerned bodies should undertake intervention measures through public teaching as well as religious teaching programs to change the traditional beliefs of the society.

- Hand craft working has been discouraged by the non-craft worker society and the continuity of the skill of handcraft working would be difficult .Therefore, culture and tourism sector of the government need to promote the importance of 'indigenous crafts'.

- Right of craft workers is not respected so the government should design programs to teach the society about equality should stand for their right.

\section{Reference}

Admas, M. (2000).Readings for diversity and social justice.New York. Routledge.

AkaleworkMengesha(2014).Roots and Manifestations of Marginalization: An Exploration ofSocio-Economic and political Facets of Minority Group in Woliatta Zone, Southern Ethiopia. Global Journals Inc. (USA).Vol.14 (7)

CSA,(2007).Summary and statistical report of the 2007population and housing census results.Addis Ababa.

DamtewYirgu,(2000). Segregation and integration of craft workers in Menz society. The case of Yelma monastic community. Unpublished Masters' Thesis, Department of social Anthropology: Addis Ababa University. Addis Ababa.

Ethiopian Human Right Council, (2009).Parallel Report Submitted to the Committee on Racial Discrimination.

EppleSusanne,( 2018).Craft workers, Hunters and Slave Descendants in Ethiopia Unpublished manuscripts of the Frobenius Institute Haberland. EH70

Finneran, N. (2003). Ethiopian evil eye belief and the magical symbolism of Iron. Folklore, 114(3) 427-433.

Freeman, D. and Pankhurst, A. (2001).Living on the edge: Marginalized minorities of craft workers and hunters 
in southern Ethiopia. Addis Ababa. Department of Sociology and Social Administration.Addis Ababa University. Addis Ababa.

Freeman, D. \& Pankhurst, A. (2003): Peripheral people: The excluded minorities of Ethiopia. London .Hurst and company.

Hoben, A. (1970). Social stratification in traditional Amhara society, in: Tuden, A. and Plotnicov, L. (eds) social stratification in Africa. New York: Landon, The free press, collier Macmillan.

Lewis, H. (1970). Wealth, influence and prestige among the Shoa society; in Tuden, A and Plotnicov, L. (eds) Social Stratification in Africa. London: The free press, Collier Macmillan.

MuluYeneabat, (2007). Pottery production an asset for women livelihood: Case study on kechene women potters in Addis Ababa. Unpublished Masters' Thesis, Graduatestudies. School of Social Work. Addis Ababa University. Addis Ababa.

Pankhurst, A. (1995). Marginalized Artisans of Southern Ethiopia: Are they 'Special Caste Groups?:Founding Workshop Bulletin of the Professional Association ofSociologists, Social Anthropologists and Social Workers of Ethiopia. Department ofSociology, Ababa University. Black well,9 (4), 17-21.

Reminick, R. (1978). The evil eye belief among the Amhara of Ethiopia. Current +anthropology. 19(3), 27-91.

TamiruBerafe, (2017).Assesing the cause and effect of social exclusion: The case of 'pot makers' in Yem Special Woreda in SNNP Rgional State in Ethiopia. Afr.J.Sci.Int.Relat.Vol.11(4) 